\title{
Cannabis use in first episode psychosis: what we have tried and why it hasn't worked
}

\author{
Michael G. McDonell ${ }^{1,2^{*}}$ and Oladunni Oluwoye $e^{1,2}$
}

\section{Keywords: Cannabis, First episode psychosis, Contingency management, Early intervention, Substance use, Co-} occurring disorders

\section{Background}

Up to $64 \%$ of individuals who have experienced a first episode of psychosis (FEP) have used cannabis, and 30\% of these have a cannabis use disorder [1,2]. Cannabis use among those with FEP is associated with negative outcomes (e.g., positive symptoms, illness severity) [1]. Given the relationship between cannabis use and psychosis, and the increasing availability of high potency tetrahydrocannabinol (THC) products, cannabis use prevention and treatment in people with FEP is a critical issue. Initial early intervention efforts that address cannabis and other substance use has been underwhelming. Early intervention programs for FEP generally include evidence-based practices focused on medication management, family psychoeducation, case management, individual therapy, and vocational services [3]. Brief or optional cognitive behavioral therapy for substance use is often integrated in early intervention programs. The question is, are these interventions sufficient in their intensity and/or duration to reduce cannabis use?

The answer appears to be no. Young people enrolled in early intervention programs do not have lower levels of cannabis or other drug use than those who receive treatment as usual [4]. In a recent secondary data analysis, we found that frequent cannabis use ( $>20$ days per month) was higher in those randomized to the early intervention treatment than those in usual care [5]. These findings are consistent with the treatment outcomes of general cooccurring disorders. Few interventions for co-occurring

\footnotetext{
* Correspondence: mmcdonell@wsu.edu

${ }^{1}$ Elson S. Floyd College of Medicine, Washington State University, 412 E. Spokane Falls Blvd, Spokane, WA 99210-1495, USA

${ }^{2}$ Program of Excellence in Addictions Research, Washington State University, Spokane, WA, USA
}

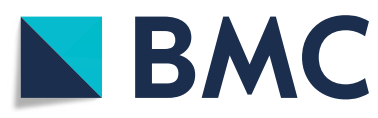

(c) The Author(s). 2019 Open Access This article is distributed under the terms of the Creative Commons Attribution 4.0 International License (http://creativecommons.org/licenses/by/4.0/), which permits unrestricted use, distribution, and

reproduction in any medium, provided you give appropriate credit to the original author(s) and the source, provide a link to the Creative Commons license, and indicate if changes were made. The Creative Commons Public Domain Dedication waiver (http://creativecommons.org/publicdomain/zero/1.0/) applies to the data made available in this article, unless otherwise stated.
$\mathrm{CM}$ is an evidence-based intervention in which individuals receive tangible rewards for submitting objective evidence of drug and alcohol abstinence [7]. Our group observed significantly lower levels of inpatient psychiatric care and psychiatric symptoms in adult patients with serious mental illness, including schizophrenia, who received $\mathrm{CM}$ for stimulant drug abstinence [8]. We found the CM intervention to be cost-effective, in part because of reductions in inpatient utilization [9]. The CIRCLE trial, by Rains et al. [10], was conducted to determine whether or not $\mathrm{CM}$ reduced cannabis use and psychiatric hospitalization, and whether it was cost-effective compared to a psychoeducational intervention for cannabis use in an early intervention program for FEP. Overall, the findings equivocally supported positive clinical outcomes that could be attributed to CM. Interpretation of these results leads us to explore the development of $\mathrm{CM}$ or other approaches as treatments for cannabis use in FEP programs. 


\section{Future directions}

Findings from the CIRCLE trial raise several considerations for future research. First, for CM to be effective, the magnitude and frequency of rewards for abstinence must be sufficient to decrease use. The unique developmental and psychiatric profiles of those with FEP mean that typical CM schedules might require modification to improve the intervention efficacy (e.g., more frequent or higher magnitude rewards). Second, a conclusive trial of CM for cannabis or other substance use requires the combination of self-report and a biochemically confirmed outcome in both the CM and control groups. Third, while we have observed CM-associated reductions in psychiatric hospitalizations, our work investigated treatment as usual in public mental health centers in the USA. The CIRCLE trial, however, investigated the impact of CM on hospitalizations within the context of specialized FEP treatment, which is designed to reduce acute psychiatric care utilization [10]. Thus, it may have been challenging for $\mathrm{CM}$ to reduce acute care, above and beyond that of typical FEP treatment. Fourth, the inclusion of a psychoeducational intervention focused on cannabis use in the control condition may have had a positive impact on cannabis use, since use in both groups declined over time. This intervention might be an effective treatment for cannabis use, and warrants further study. Finally, the CIRCLE trial raises important questions about the feasibility of CM for FEP programs; the authors describe the challenges of adding a simple intervention, such as CM, to an already intensive, multi-component treatment for FEP [10]. Additional work investigating how CM and other substance use treatments can be implemented in FEP care is greatly needed.

\section{Conclusions}

In the past decade, early intervention programs for FEP have revolutionized the treatment of schizophrenia. This momentum provides the opportunity to integrate interventions that address cannabis and substance use problems early in the course of illness, with the goal of preventing the negative effects of substance use on people with psychosis. With the increasing availability of high potency THC products, and the global movement towards decriminalization, cannabis use presents a formidable and important area of focus for FEP treatment providers. Studies such as the CIRCLE trial indicate that developing an effective treatment for cannabis use in this population will not be easy. A one-size-fits-all approach is unlikely to be effective given the homogeneity of cannabis use (e.g., differences in frequency or motivations for use) in young people with FEP. Effective strategies are also needed to prevent people with FEP from using cannabis in the first place. Future research focusing on implementation and dissemination issues is needed to close the gap between research and practice improvement. As a field, we should strive to develop truly integrated early interventions for psychosis and substance use to help improve the lives of young people with, or at high risk of, these commonly cooccurring disorders.

\section{Acknowledgments}

Not applicable.

\section{Authors' contributions}

The authors alone are responsible for the content and writing of this paper. All authors read and approved the final manuscript.

\section{Funding}

Not applicable.

\section{Availability of data and materials \\ Not applicable.}

Ethics approval and consent to participate

Not applicable.

\section{Consent for publication}

Not applicable.

\section{Competing interests}

The authors declare that they have no competing interests.

Received: 29 August 2019 Accepted: 6 September 2019

Published online: 28 October 2019

\section{References}

1. Oluwoye O, Monroe-DeVita M, Burduli E, Chwastiak L, McPherson S, McClellan JM, et al. The impact of tobacco, alcohol, and cannabis use in patients with first-episode psychosis: data from the national RAISE-ETP study. Early Intervent Psychiatry. 2019;13(1):142-6.

2. Barnes TR, Mutsatsa SH, Hutton SB, Watt HC, Joyce EM. Comorbid substance use and age at onset of schizophrenia. Br J Psychiatry. 2006;188(3):237-42.

3. Kane JM, Robinson DG, Schooler NR, Mueser KT, Penn DL, Rosenheck RA, et al. Comprehensive versus usual community care for first-episode psychosis: 2-year outcomes from the NIMH RAISE early treatment program. Am J Psychiatry. 2015;173(4):362-72.

4. Cather C, Brunette MF, Mueser KT, Babbin SF, Rosenheck R, Correll CU, et al. Impact of comprehensive treatment for first episode psychosis on substance use outcomes: a randomized controlled trial. Psychiatry Res. 2018;268:303-11.

5. Alcover KC, Oluwoye O, Kriegel L, McPherson S, McDonell MG. Impact of first episode psychosis treatment on heavy cannabis use: secondary analysis on RAISE-ETP study. Schizophr Res. 2019:211:86-7.

6. Drake RE, O'Neal EL, Wallach MA. A systematic review of psychosocial research on psychosocial interventions for people with co-occurring severe mental and substance use disorders. J Subst Abus Treat. 2008;34(1):123-38.

7. Petry NM, Bickel WK, Tzanis E, Taylor R, Kubik E, Foster M, et al. A behavioral intervention for improving verbal behaviors of heroin addicts in a treatment clinic. J Appl Behav Anal. 1998;31(2):291-7.

8. McDonell MG, Srebnik D, Angelo F, McPherson S, Lowe JM, Sugar A, et al. Randomized controlled trial of contingency management for stimulant use in community mental health patients with serious mental illness. Am J Psychiatry. 2013;170(1):94-101.

9. Murphy SM, MCDonell MG, McPherson S, Srebnik D, Angelo F, Roll JM, et al. An economic evaluation of a contingency-management intervention for stimulant use among community mental health patients with serious mental illness. Drug Alcohol Depend. 2015;153:293-9.

10. Rains LS, Marston L, Hinton M, Marwaha S, Craig T, Fowler D, et al. Clinical and cost-effectiveness of contingency management for cannabis use in early psychosis: the CIRCLE randomised clinical trial. BMC Med. 2019;17:1):1-17.

\section{Publisher's Note}

Springer Nature remains neutral with regard to jurisdictional claims in published maps and institutional affiliations. 